Document downloaded from:

http://hdl.handle.net/10251/49923

This paper must be cited as:

Espejo, Azahara; Aguinaco, Almudena; Amat, Ana M.; et ál.. (2014). Some ozone advanced oxidation processes to improve the biological removal of selected pharmaceutical contaminants from urban wastewater. Journal of Environmental Science and Health Part A-Toxic/Hazardous Substances\&Environmental Engineering. 49(4):410421. doi:10.1080/10934529.2014.854652.

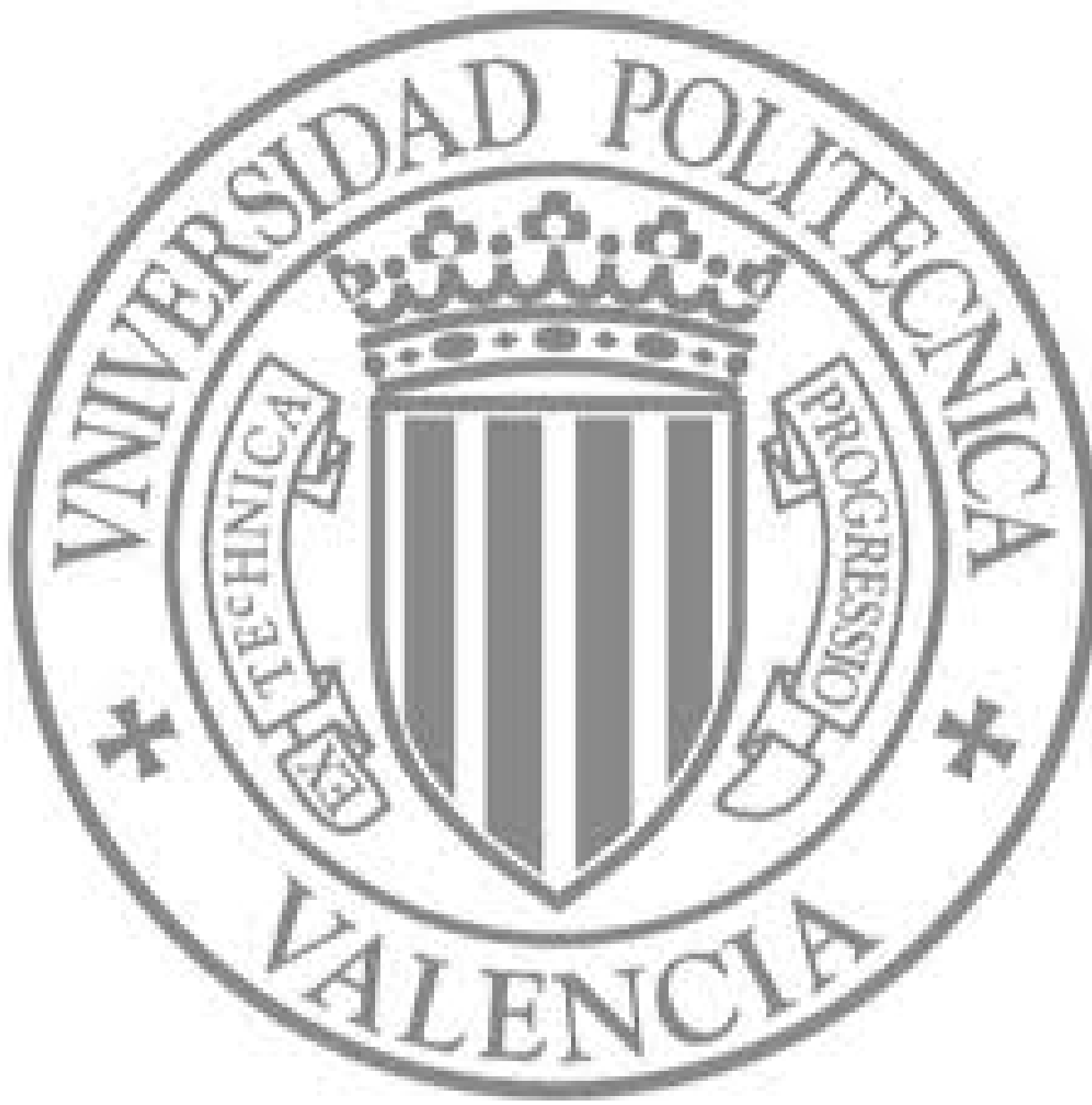

The final publication is available at

http://dx.doi.org/10.1080/10934529.2014.854652

Copyright Taylor \& Francis: STM, Behavioural Science and Public Health Titles 


\title{
Some ozone advanced oxidation processes to improve the biological removal of selected pharmaceutical contaminants from urban wastewater
}

\author{
A. Espejo ${ }^{a}$, A. Aguinaco ${ }^{a}$, A.M. Amat ${ }^{\text {b }}$, F. J. Beltrán*a \\ ${ }^{a}$ Departamento de Ingeniería Química y Química Física. Universidad de \\ Extremadura, Avenida de Elvas S/N, 06071 Badajoz. Spain \\ ${ }^{b}$ Departamento de Ingeniería Textil y Papelera. Universidad Politécnica de \\ Valencia. Alcoy. 03801 Alicante. Spain
}

\begin{abstract}
Removal of nine pharmaceutical compounds: acetaminophen, AAF, antipyrine, ANT, caffeine, CAF, carbamazepine, CRB, diclofenac, DCF, hydrochlorothiazide, HCT, ketorolac, KET, metoprolol, MET and sulfamethoxazole, SMX, spiked in a primary sedimentation effluent of a municipal wastewater has been studied with sequential aerobic biological and ozone advanced oxidation systems. Ozone, UVA black light and $\mathrm{Fe}$ (III) or $\mathrm{Fe}_{3} \mathrm{O}_{4}$ constituted the chemical systems. During the biological treatment, only AAF and CAF were completely eliminated, MET, SMX and HCT reached partial removal rates and the rest of compounds were completely refractory (HRT=24 h). With any ozone advanced oxidation process applied, the remaining pharmaceuticals disappear in less than 10 minutes. The presence of $\mathrm{Fe}_{3} \mathrm{O}_{4}$ or $\mathrm{Fe}(\mathrm{III})$ during photocatalytic ozonations also allowed mineralization increases, compared to the single ozonation process, from $13 \%$ to about $35 \%$. Biodegradability of the treated wastewater increased $50 \%$ in the biological process and other $150 \%$ after the ozonation processes. Both untreated and treated wastewater was non toxic for Daphnia Magna except when Fe(III) was used in photocatalytic ozonation. In this case, the ferryoxalate formed seems to be the reason of toxicity. Kinetic information on ozone processes reveals that pharmaceuticals at the very low concentrations they are found in urban wastewater are mainly removed through free radical oxidation.
\end{abstract}


Keywords: Aerobic Processes, Biodegradation, Environmental Preservation, Wastewater treatment, emerging contaminants, ozone advanced oxidation processes

Corresponding author. (Tel.: +0034924289385); e-mail: fbeltran@unex.es; FAX: +0034924289385 .

\section{Introduction}

Now days the presence of pharmaceuticals and their metabolites in urban wastewater, mainly as a consequence of the uptake of medicines, is largely known [1-5]. Because of the presence of active biochemical principles in their molecules, pharmaceuticals, once released to water environments, present potential hazardous effects on humans and aquatic ecosystems [6,7]. Removal of these contaminants should be achieved in conventional wastewater treatment plants, mainly through biological oxidation, but these systems are not specifically designed for this role. In fact, as rule of thumb, emerging contaminants pass unaffected in a great extent through the classical unit operations of wastewater treatment plants [8-11]. However, because of their persistent and potentially hazardous character, these compounds may negatively affect living organisms in the aquatic environment and, consequently, more advanced treatments are needed to complete their removal from wastewater. In this sense, several researches have shown that ozonation and advanced oxidation processes (AOPs) have been successfully used to oxidize these contaminants from water [12-14]. Thus, literature has already reported many works where laboratory prepared aqueous solutions or biologically treated urban wastewater spiked with emerging contaminants (ECs) are successfully treated with AOPs. However, results on the combined effect of biological and advanced oxidation processes are required in order to check the real improvement in removal rates when these contaminants are initially present in the wastewater. Thus, in this work, an urban wastewater doped with nine ECs has been biologically and chemically treated in two sequential steps with activated sludge and different AOPs, respectively. Activated sludge was collected from a secondary biological treatment of an urban wastewater treatment plant and ozone, UVA light and iron type catalysts ( $\mathrm{Fe}(\mathrm{III})$ and $\mathrm{Fe}_{3} \mathrm{O}_{4}$ ) were the constituents agents of AOPs applied. The ECs added to the wastewater were acetaminophen (AAF), antipyrine (ANT), caffeine (CAF), 
carbamazepine (CRB), diclofenac (DCF), hydrochlorothiazide (HCT), ketorolac (KET), metoprolol (MET) and sulfamethoxazole (SMX). These compounds are very used both for medical or social purposes and are commonly identified in urban wastewaters [15-17].

\section{Materials and methods}

\subsection{Primary wastewater effluent and chemicals}

Wastewater from the first sedimentation unit or primary treatment effluent of the Rincón de Caya Wastewater Treatment Plant (WWTP) (Badajoz, Spain) was spiked with the nine selected pharmaceuticals with an initial concentration of $200 \mu \mathrm{g} \mathrm{L}^{-1}$ each one. This concentration, although something higher than the actual ones encountered in urban wastewater, that usually reach as much as some $\mu \mathrm{g} \mathrm{L}^{-1}[12,18]$ allowed a more accurate and fast quantitative chemical analysis with our available equipments (see below). The physico-chemical characterization of the wastewater used is summarized in Table 1. Pharmaceuticals and $\mathrm{Fe}\left(\mathrm{ClO}_{4}\right)_{3} \cdot \mathrm{xH}_{2} \mathrm{O}$ were purchased from Sigma-Aldrich (Spain), and $\mathrm{Fe}_{3} \mathrm{O}_{4}$ from Bendix. Other chemicals were at least reagent grade and used as received.

The molecular structures of pharmaceuticals used are shown in Figure 1. These contaminants were chosen because they were of different families of pharmaceutical compounds: analgesic, beta-blockers, antiepileptic, antibiotic, etc, and are usually detected in urban wastewater [15-17].

\subsection{Activated sludge}

Aerobic biological treatment was carried out using activated sludge as biomass. This biomass was collected from the returning pipe of the activated sludge in Rincón de Caya WWTP (Badajoz, Spain).

\subsection{Experimental Setup}

\subsubsection{Biological Treatment}


Aerobic biological oxidation experiments were carried out in batch mode in a $30 \mathrm{~L}$ parallelepiped tank provided with mechanical stirring and aerated through several diffusers to reach $3.0 \mathrm{mg} \mathrm{O}_{2} \mathrm{~L}^{-1}$ (see Figure 2). The reactor was charged with the primary effluent from the urban WWTP spiked with pharmaceuticals mixtures. The activated sludge added varied between 1 and $3 \mathrm{mg} \mathrm{L}^{-1}$ of Mixed Liquor Volatile Suspended Solids (MLVSS). Hydraulic retention time was between 7 and $24 \mathrm{~h}$.

Steadily, samples were withdrawn from the reactor and analyzed for contaminant concentrations, total organic carbon (TOC), chemical oxygen demand (COD) and ultraviolet absorbance at $254 \mathrm{~nm}\left(\mathrm{Abs}_{254}\right)$. Also, biochemical oxygen demand after five days $\left(\mathrm{BOD}_{5}\right)$ was measured at the start and end of experiments. In some experiments, the ecotoxicity to Daphnia magna was also determined. Prior to the analysis, the solid was removed from samples by a 5415D Eppendorf Centrifuge (Hamburg, Germany) and further filtration through a Millex HV filter (Millipore, 22 $\mu \mathrm{m})$.

\subsubsection{Advanced Oxidation Processes}

Experiments were carried out in semibatch mode in a $1 \mathrm{~L}$ cylindrical borosilicate glass reactor that was provided with gas inlet (through a diffuser placed at the bottom of the reactor) and outlet, mechanical stirring and sampling port (see Figure 3). Ozonation experiments were carried out with an ozone-oxygen gas mixture flow of $35 \mathrm{~L} \mathrm{~h}^{-1}$. Ozone was produced from pure oxygen with a Sander Laboratory Ozone Generator. In experiments requiring UVA light, the aqueous solution was irradiated with two $15 \mathrm{~W}$ tubular black light (BL) lamps (HQ Power Lamp 15TBL) emitting mainly $365 \mathrm{~nm}$ radiation. The lamps were installed on opposing walls outside the reactor in a closed box. The reactor walls were covered by aluminium foil to enhance radiation. Ferrioxalate actinometry was used to determine the incident flux of radiation that was found to be $7.05 \pm 0.05 \times 10^{-5}$ Einstein $\min ^{-1}$

During each experiment, samples were withdrawn from the reactor to analyze pharmaceuticals and oxalic acid concentration, TOC, COD, initial and final $\mathrm{BOD}_{5}$, $\mathrm{Abs}_{254}$, total iron concentration and dissolved ozone concentration.

\subsection{Analytical methods}


High performance liquid chromatography (HPLC) was applied using LaChrom Elite equipment (Hitachi, Spain) to determine the pharmaceuticals concentrations in samples. HPLC was provided with a Phenomenex (Spain) Synergi Hydro-RP column $(250 \times 4.60 \mathrm{~mm}$, particle size $4 \mu \mathrm{m}, 80 \AA)$, an L-2450 DA detector and EZ Chrom software for data treatment. The injection volume was $99 \mu \mathrm{L}$. The mobile phase used in the chromatographic separation consisted of a binary mixture of solvents A (Acetonitrile) and B (acidified water with $0.1 \%$ formic acid). A nonisocratic mobile phase gradient program was used: it consisted of 40 min linear gradient from $10 \%$ to $100 \%$ of $\mathrm{A}$ with a flow rate of $0.2 \mathrm{~mL} \mathrm{~min}^{-1}$. The separation was monitored at different absorbance wavelength as shown in Table 2. Detection limit for accurate measurements of concentrations was about $2 \mu \mathrm{g} \mathrm{L}^{-1}$. From standard solutions, the analysis was repeated to establish the precision of the method that resulted to be $\pm 2 \%$ while accuracy was $1.3 \%$.

For oxalic acid concentration, a Supelcogel C-610 column was used. In this case, the mobile phase, at a flow rate of $0.75 \mathrm{~mL} \mathrm{~min}^{-1}$, was ultrapure water acidified at $\mathrm{pH}$ 2.5 with phosphoric acid ( $0.1 \%$ concentration). Detection was made with an L-2455 Hitachi Diode Array detector at $210 \mathrm{~nm}$ and injection volume was $40 \mu \mathrm{L}$.

TOC was determined by a TOC-V $\mathrm{V}_{\mathrm{CSH}}$ Shimadzu Analyzer (VWR, Spain). In this case, detection limit, precision and accuracy were $50 \mu \mathrm{g} \mathrm{L}^{-1}, 3 \%$ and $1.5 \%$ according to Shimadzu manufacturer, respectively. COD was measured following standard dichromate reflux method in a Dr. Lange spectrophotometer [19] (Precision: 3\%). BOD was measured following the respirometric method [20] (Precision: 15\%). Total iron concentration was determined by the ferrozine method [21] that, briefly, consisted in the reduction to $\mathrm{Fe}(\mathrm{II})$ and further formation of a violet complex with the ferrozine reagent. Finally, for the ozonation runs, dissolved ozone concentration in aqueous solutions was analyzed by the indigo method [22]. According to the authors this method presents $2 \%$ precision and a detection limit of $10^{-7} \mathrm{M}$ for absorbance measurements in $5 \mathrm{~cm}$ cell. In this work, $1 \mathrm{~cm}$ cell was used so that detection limit was $5 \times 10^{-7} \mathrm{M}$. Ozone in the gas phase was monitored by means of an Anseros Ozomat ozone analyser. The $\mathrm{pH}$ was tested with a $\mathrm{pH}$ meter (Crison GLP$21+)$. Prior to the analysis, the solid was removed from samples by filtration through a Millex-HV filter (Millipore, $0.22 \mu \mathrm{m}$ ). 


\subsection{Test organisms}

Daphnia magna are freshwater invertebrates of the order Cladocera, more commonly known as the water flea. They have a relatively short life (7-8 weeks at $20{ }^{\circ} \mathrm{C}$ ) and reach sexual maturity within 6-8 d of leaving the brood chamber [23]. Due to their size, ease of culture and short life span, D. magna are extensively used as a representative freshwater invertebrate species in ecotoxicological studies.

\subsubsection{Daphnia acute immobilisation test}

Acute toxicity Daphnia tests were conducted following the commercial test kit DAPHTOXKIT $\mathrm{F}^{\mathrm{TM}}$ (Creasel BVBA; Deinze, Belgium) using the water flea $D$. magna. These tests were performed in accordance with testing conditions prescribed by OECD Guideline 202 [24] (Daphnia sp. Acute Immobilisation Test). Experiments were run at temperatures of $20 \pm 2{ }^{\circ} \mathrm{C}$ and 6000 lux. Twenty daphnids younger than $24 \mathrm{~h}$ were used for the controls and each assayed solution subdivided in four replicates each containing five daphnids. Immobility was observed after 24 and $48 \mathrm{~h}$ with the latter being the endpoint for effect calculation. A Daphnia was considered to be immobile if it did not move after $15 \mathrm{~s}$ of gentle agitation. Immobilisation of the animals leads to their death because of inherent impossibility of capturing food.

A limit test was performed with the solutions in order to demonstrate that the $\mathrm{EC}_{50}$ $\left(\mathrm{EC}_{50}\right.$ is the concentration estimated to immobilise 50 per cent of the daphnids within a stated exposure period) is greater than the concentration sampled. When the percentage of immobilisation is minor or equal $10 \%$ at the end of the test $(48 \mathrm{~h})$, it can be considered that solution does not show acute toxicity to D. magna. Potassium dichromate $\left(\mathrm{K}_{2} \mathrm{Cr}_{2} \mathrm{O}_{7}\right)$ was the reference chemical used.

\section{Results and Discussion}

\subsection{Biological treatment}

First, a series of biological experiments were carried out. As an example of the results obtained, Figure 4 shows the changes with time (up to 24 hours) of the remaining dimensionless concentration of the selected pharmaceuticals. As it can be 
seen, only three compounds: AAF, CAF and MET showed significant removal rates. In fact the first two are completely removed in less than 10 hours. The rest of compounds were completely refractory to biological oxidation, except SMX and HCT that presented less than $25 \%$ and $15 \%$ conversions in 24 hours treatment.

It should be noted, that in this work no attempt was made to elucidate the mechanism of removal during biological oxidation since two possible ways can develop: biological oxidation itself and adsorption on activated sludge. The objective was only to check the order of removal to be compared to the further chemical oxidation process. In any case, it can be highlighted that previous works report adsorption as the main way of pharmaceutical removal from urban wastewater [25-30]. In Figure 5 , on the other hand, the changes observed on TOC with time corresponding to the experiment of Figure 4 are presented. Results of COD with time showed a similar trend. In this case, there is a deep decrease of COD after about the first 2 hours of treatment. After this reaction time, COD was practically unaffected. Regarding TOC evolution (see Figure 5), this parameter reduces to reach a conversion of about $55 \%$ during the first 10 hours of treatment and then slowly reaches $60 \%$ elimination after 24 hours.

The effect of activated sludge concentration was also studied. However, in this case, changes of initial MLVSS loading did not lead to any significant variation of the remaining concentration of pharmaceuticals studied and COD and TOC (results not shown).

\subsection{Advanced oxidation processes}

In a second series of experiments, advanced oxidation processes were applied to the biologically treated urban wastewater. For these cases, 7 hours laboratory biologically treated wastewater was subsequently subjected to advanced chemical oxidation technologies. This was due to the fact that the wastewater treatment plant of Badajoz has a 7 hour hydraulic residence time (HRT) for the biological operation. Then, in these samples concentration of pharmaceuticals was the one they had at the end of the laboratory biological process. Thus, the biologically treated wastewater only had 7 out of 9 initial pharmaceuticals. The oxidation processes applied were ozonation, photocatalytic oxidation and photocatalytic ozonation. Also, direct photolysis experiments were carried out for comparative reasons. Two iron catalysts 
were used, $\mathrm{Fe}(\mathrm{III})$ and magnetite $\left(\mathrm{Fe}_{3} \mathrm{O}_{4}\right)$. Photolysis of these iron catalysts leads to hydroxyl radicals as has been shown in previous works [31,32]. As expected, direct photolysis of any of the 7 remaining compounds did not lead to positive results since these compounds do not absorb radiation in the wavelength emitted by the UVA lamp used in this work. Also, photocatalytic oxidation with the iron catalysts used did not either lead to any pharmaceutical degradation As shown in Figure 6, as example, ozone processes were the only ones among those studied here that effectively allowed significant or even total elimination of the pharmaceuticals studied. This, on the other hand, confirmed previous results of the ozonation of some of these compounds in ultrapure water at a much higher concentration [33-35]. It should be highlighted; however, that total removal means that pharmaceuticals were in water at concentrations below their detection limit of the HPLC method applied that was about $2 \mu \mathrm{g} \mathrm{L}^{-1}$. Thus, in Figures $6 \mathrm{a}, \mathrm{b}, \mathrm{c}$ results of the ozone processes studied here are shown. As can be seen these figures show, as examples, the changes observed with time of the concentrations of three out of seven pharmaceuticals still present in the urban wastewater after a 7 hours biological treatment period. These compounds are antipyrine, hydrochlorothiazide and ketorolac. The other 4 compounds show similar results and removal rates. As can be seen from Figures 6 pharmaceuticals compounds are eliminated in less than 10 minutes, regardless of the ozone process applied. On the contrary to the results observed with the pharmaceutical compounds, global parameters that measure the organic content or the presence of unsaturated groups (benzene rings, carbon double bonds, etc) in the biologically treated urban wastewater, that is, TOC or $254 \mathrm{~nm}$ absorbance show different results depending on the ozone process applied. Thus, Figure 7 depicts the time variation of percentage removal of TOC in the three ozone processes investigated.

As it can be seen the single ozone process leads to about $13 \%$ TOC reduction after 30 minutes treatment while about 32 and $36 \%$ TOC reductions are achieved with the $\mathrm{Fe}_{3} \mathrm{O}_{4}$ and $\mathrm{Fe}(\mathrm{III})$ photocatalytic ozonation processes, respectively. COD also showed similar results.

In Figure 8, on the other hand, the time changes observed in the $254 \mathrm{~nm}$ absorption of treated samples is presented. As it can be observed, photocatalytic ozonation allowed higher percentage removal of unsaturated compounds than ozonation alone 
(i.e. after 30 minutes reaction, 60 and 50\% removal are achieved in the photocatalytic and non photocatalytic ozone processes, respectively).

\subsection{Ozone consumption}

For the ozonation processes investigated the consumption of ozone per TOC eliminated has also been determined following equation (1):

$$
\Psi_{O 3}=\frac{m_{O_{3} i n} \cdot t-\left(\int m_{\mathrm{S}_{3} \text { out }} d t+C_{O_{3}} \cdot V\right)}{\left(T O C_{0}-T O C_{t}\right) \cdot V}
$$

where $\mathrm{m}_{\text {in }}$ and $\mathrm{m}_{\text {out }}$ represent the ozone molar rates at the reactor inlet and outlet, respectively, $\mathrm{C}_{\mathrm{O} 3}$ the concentration of ozone dissolved in water, $\mathrm{V}$ the reactor volume, $\mathrm{t}$ the reaction time and $\mathrm{TOC}_{0}$ and $\mathrm{TOC}_{\mathrm{t}}$ values of $\mathrm{TOC}$ at the start of ozonation and at time t, respectively. Table 3 presents the results obtained.

As it is observed from Table 3 photocatalytic ozonation processes consume lesser ozone amounts than the single ozonation process per mg of consumed TOC. This means that regarding the mineralization of organic compounds and economy to reduce the costs of ozone production, photocatalytic ozonation is a more economically selective process.

\subsection{Partial Oxidation Yield}

In order to quantitatively establish the oxidation capacity of the systems studied the partial oxidation yield, $\mu_{\text {partox }}$, was also calculated [36]. This parameter is defined as follows:

$$
\mu_{\text {partox }}=\frac{C O D_{\text {partox }}}{C O D_{0}-C O D} \times 100
$$

where

$$
C O D_{\text {partox }}=\left(\frac{C O D_{0}}{T O C_{0}}-\frac{C O D}{T O C}\right) T O C
$$

The partial oxidation yield indicates the percentage of COD removed that has not been mineralized. These parameters were also calculated for the biological process. Thus, for this first treatment the partial oxidation yield was $1.1 \%$ which means that $98.9 \%$ of COD removed was mineralized. 
For the ozone processes, results were as follows: In single ozonation $100 \%$ mineralization of the COD eliminated was achieved in 10 minutes. After this time no values can be considered since no further COD reductions were observed (see also Figure 7). In photocatalytic ozonation, regardless of the type of catalyst, percentage mineralization increases up to $85 \%$ of COD eliminated (35\%) in the first 20 minutes. After this reaction time, remaining COD was unaltered as in the case of single ozonation.

\subsection{Oxidation State of Carbon}

The average oxidation state of carbon, AOSC, is another parameter, based on the measurements of TOC and COD. This parameter gives an estimation of the importance of oxygenated compounds present in water. It varies from -4 (that corresponds to organics such as methane) to +4 (that corresponds to organics such as carbon dioxide). In an oxidation process, regarding AOSC, what really matters is the increment observed in AOSC during the oxidation process, that is, $\triangle[\mathrm{AOSC}]$. Both parameters are defined as follows [36]:

$$
\begin{gathered}
A S O C=\frac{4\left(T O C-\frac{12}{32} C O D\right)}{T O C} \\
\Delta[A O S C]=4\left(\frac{C O D_{0}}{T O C_{0}}-\frac{C O D}{T O C}\right) \frac{12}{32}
\end{gathered}
$$

For the biological treatment, AOSC varies from -2 for the primary sedimentation wastewater (pharmaceuticals included) to +1 for the 7 hours biologically treated wastewater, that is, the increment of AOSC observed during the biological period $(\Delta[\mathrm{AOSC}])$ was 3 . These results indicate that the biological treatment only lead to a partial state of oxidation of the remaining carbon.

For the ozone processes the results were: For single ozonation no increment of oxidation state number was observed while for the photocatalytic ozone processes a 0.3 increment was reached in 1 hour of reaction. However, it should be reminded that these parameters and also the partial oxidation yield have to be taken with caution since their values may also be due to the presence of inorganic substances that contribute to increase COD. 


\subsection{Biodegradability}

The ratio between $\mathrm{BOD}$ and $\mathrm{COD}$ is often defined as a measure of the biodegradability of the wastewater. Here, in this work this parameter has been measured at the start and end of the biological and chemical experiments. The results are shown in Table 4.

As it can be seen from Table 4 a 50\% increase of biodegradability is reached after the biological treatment while adding a further ozonation process leads to another $100 \%$ increase as average. However, if biodegradability of non treated wastewater is compared to the one at the end of the sequence of biological plus chemical treatments, an average $200 \%$ increase of biodegradability is observed.

\subsection{Ecotoxicity}

For checking the toxicity of the raw wastewater and biological and chemically treated wastewaters, D. magna immobilisation tests were carried out. The results are shown in Table 5. An $\mathrm{EC}_{50} 24 \mathrm{~h}$ of $1.88 \mathrm{mg} \mathrm{L}^{-1}$ was obtained for potassium dichromate, which is within range of the $0.6-2.1 \mathrm{mg} \mathrm{L}^{-1}$ stipulated in the ISO 6341 to ensure test validity. No swimming inhibition was observed in the controls exposed in each plate. As it can be seen from Table 5 only wastewater treated with $\mathrm{Fe}$ (III) photocatalytic ozonation results in a given degree of ecotoxicity. This could be attributed to the formation of the ferrioxalate complex during $\mathrm{Fe}$ (III) photocatalytic ozonation as deduced from Figure 9. Thus, Figure 9 presents the variation with time of total dissolved iron concentration during both ozone and ozone-free photocatalytic processes study in this work. As it can be seen from Figure 9 during $\mathrm{Fe}_{3} \mathrm{O}_{4}$ photocatalytic runs, regardless of the presence of ozone, there is no iron leaching while during $\mathrm{Fe}(\mathrm{III})$ photocatalytic runs, the presence of ozone gives rise to a decrease of the dissolved iron concentration during the first 30 minutes undoubtedly due to the formation of ferryoxalate. Oxalic acid is a usual end product of ozonation runs [37-39] that has also been detected in this work. However, in the absence of ozone, no decrease of total iron concentration is observed which was due to the absence of oxalic acid formation during this run. Toxicity of ferryoxalate complex towards D. magna was reported by Trovó et al. $[40,41]$ when they observed this 
phenomenon during the photo-Fenton oxidation of amoxiciline and paracetamol (acetaminophen) with $\mathrm{FeSO}_{4}$ and potassium ferryoxalate as catalysts. These authors reported $100 \%$ D. magna mobility inhibition in a control run where ferryoxalate was present.

\subsection{Kinetic aspects}

As it can be deduced from this work, ozone-free photocatalytic oxidation processes require reaction times longer than 1 hour to observe some significant degradation of compounds and TOC. Ozone processes, on the other hand, are complex gas-liquid systems involving series-parallel reactions in water, and the kinetics depends on both ozone mass transfer and chemical reactions [42]. In order to establish the corresponding reaction rate expression, it is first necessary to know the kinetic regime where these reactions develop, that is, basically to know if the reactions are slow or fast compared to mass transfer rates. For so doing, the Hatta number of these reactions has to be determined. The Hatta number, Ha, of a second order gas-liquid reaction, as the ones ozone undergo in water, between ozone and a compound $\mathrm{M}$, is defined as follows:

$$
H a=\frac{\sqrt{k_{D} \cdot D_{O 3} \cdot C_{M}}}{k_{L}}
$$

where $\mathrm{k}_{\mathrm{D}}, \mathrm{D}_{\mathrm{O} 3}, \mathrm{C}_{\mathrm{M}}$ and $\mathrm{k}_{\mathrm{L}}$ are the rate constant of the reaction between ozone and compound $\mathrm{M}$, the ozone diffusivity in water, the concentration of compound $\mathrm{M}$ and the liquid phase mass transfer coefficient, respectively. Table 6 shows the values of Ha corresponding to the ozone-pharmaceutical reactions at the conditions of the start of ozone processes, that is, with values of $\mathrm{C}_{\mathrm{M}}$ corresponding to those of the pharmaceuticals after the biological treatment. It should be noted that due to the lack of data found in literature on rate constants of direct ozone reactions at $\mathrm{pH} 3$ most of Ha values have been determined with the rate constants at $\mathrm{pH} 7$ and only a few of them at the $\mathrm{pH}$ of ozone reactions, that is, at $\mathrm{pH} 3$. As it can be seen from Table 6, Ha shows values higher than 0.3 except for the cases of HCT and MET ozone reactions. According to gas-liquid reaction kinetic theory [48] this means that only the ozone-HCT and ozone- MET are slow reactions. In this case, as shown in a previous work [50] removal of HCT and MET can be due to the competitive 
contributions of both their direct ozone reaction and hydroxyl radical reaction. Thus, in a semibatch well agitated reactor, as in this work, the mass balance of HCT and MET can be expressed as follows:

$$
-\frac{d C_{M}}{d t}=k_{D} C_{O 3} C_{M}+k_{H O} C_{O H} C_{M}
$$

where $\mathrm{C}_{\mathrm{M}}$ and $\mathrm{C}_{\mathrm{O} 3}$ are the concentrations of $\mathrm{HCT}$ or MET and dissolved ozone in water, respectively, and $\mathrm{k}_{\mathrm{HO}}$ is the the rate constant of the reaction of hydroxyl radicals and the pharmaceutical compound. For the rest of pharmaceuticals, however, both ozone direct reaction and mass transfer through the liquid film close to the gas-liquid interphase simultaneously develop so that equation (7) does not hold. Accordingly, if pharmaceuticals can be removed in the ozone processes through both direct and hydroxyl radical reactions [42] (case of MET and HCT) the application of an ozone involving AOP is, a priori, advisable to improve their removal from water. For these two pharmaceuticals, the percentage contribution of the direct ozone reaction $(\% \mathrm{DR})$ for their removal has been calculated with the aid of equation (8):

$$
\% D C=\frac{k_{D} C_{O 3} C_{M}}{-\frac{d C_{M}}{d t}} \times 100
$$

Table 7 shows the values of \%DC corresponding to the removal of MET and HCT. As it can be seen, HCT is mainly removed by hydroxyl radical oxidation regardless of the ozone process while some contribution of the direct ozone reaction is observed for the case of MET. In any case, the increase of reaction time leads to an increase of the contribution of the direct ozone reaction. For example, in the ozone process, after 10 minutes, remaining concentrations of MET and HCT are 30 and $17 \mu \mathrm{g} \mathrm{L}^{-1}$ and contribution of the direct ozone reaction was 35.9 and $12.7 \%$, respectively. Similar trends are observed for photocatalytic ozone oxidations. According to these results some prediction can be made on the removal of the pharmaceuticals in ozone processes when present in actual wastewater at very low concentration (i.e. $200 \mathrm{ng} \mathrm{L}^{-}$ $\left.{ }^{1}\right)$. At this concentration, Hatta numbers of any ozone direct reaction are much lower than 0.3 (regardless of $\mathrm{pH} 3$ or 7), that is, any ozone-pharmaceutical reaction is slow and equation (8) holds. Total accumulation rates $\left(-\mathrm{dC}_{\mathrm{M}} / \mathrm{dt}\right)$ and dissolved ozone concentration are needed to apply equation (8). Predictions of these rates when the pharmaceutical concentration is very low can be made by assuming a pseudofirst 
order kinetics for these processes. In fact, this assumption holds for the cases of HCT and MET ozonation. Thus, predicted pharmaceutical reaction rate would be:

$$
-\frac{d C_{M}}{d t}=k^{\prime} C_{M}
$$

Least squares analysis of the logarithm of MET and HCT concentration with time gives the values of $\mathrm{k}^{\prime}$ shown in Table 8 . As it can be observed, photocatalytic ozonation processes lead to higher k' values than ozonation alone. However, the effect on compounds is different. Thus, Fe(III) seems to be more recommended to remove MET during photocatalytic ozonation than $\mathrm{Fe}_{3} \mathrm{O}_{4}$. The contrary situation is observed for HCT with magnetite as the most appropriate catalyst to improve the reaction rate. From theses k' values, for a concentration of $200 \mathrm{ng} \mathrm{L}^{-1}$ accumulation rates, left term of equation (9), of MET and HCT were calculated. The dissolved ozone concentration is also needed to apply equation (8). For this concentration a value $10^{-7} \mathrm{M}$ was assumed. This is a reasonable assumption for the start of the wastewater ozonation process since at 2 minutes ozonation a value of $5 \times 10^{-7} \mathrm{M}$ was experimentally determined. With $\mathrm{k}^{\prime}, \mathrm{k}_{\mathrm{D}}, \mathrm{C}_{\mathrm{O} 3}$ and $\mathrm{C}_{\mathrm{M}}$ the contribution of the direct reaction was then predicted from equation (8). Results are also shown in Table 8. It can be seen that also for very low pharmaceutical concentrations and regardless of the ozonation process type hydroxyl radical oxidation is the main way of pharmaceutical (HCT and MET) removal. Thus, application of an advanced oxidation process such as photocatalytic ozonation that increases the concentration of hydroxyl radicals is advisable.

\section{Conclusions}

From this work, the following conclusions can be derived:

Aerobic biological oxidation of the utilized urban wastewater spiked with the nine pharmaceutical studied only completely removes AAF and CAF in 7 hours retention time. Most of compounds remain partially or completely refractory to the biological step.

Application of any ozone processes removes the remaining pharmaceuticals in less than 10 minutes.

Biodegradability of the treated wastewater increases both after the biological and chemical oxidation steps in $50 \%$ and $100 \%$, respectively. Compared to the untreated 
wastewater, a total increase of about $200 \%$ is observed after the sequence of treatments.

After 30 minutes ozone process oxidation, $\mathrm{Fe}_{3} \mathrm{O}_{4}$ photocatalytic ozonation shows the lowest ozone consumption per TOC eliminated.

Parameters measuring the oxidation improve of the wastewater (partial oxidation yield or oxidation state of carbon) also increase especially during the ozone processes.

Ecotoxicity to Daphnia Magna resulted negative in all the cases except when Fe(III) was used as photocatalyst likely because of the formation of ferryoxalate.

Application of gas-liquid reaction kinetic concepts to the ozone process results indicates that pharmaceuticals in urban wastewater, at low concentration $\left(<\mu \mathrm{g} \mathrm{L}^{-1}\right)$ are removed from hydroxyl radicals instead of direct reactions. At hundreds of $\mu \mathrm{g} \mathrm{\textrm {L } ^ { - }}$ ${ }^{1}$, however, some pharmaceuticals (SMT, DCF, ANT, KET) are mainly eliminated through their direct reactions with ozone.

\section{Acknowledgements}

Authors thank the Spanish CICYT and Feder funds for the economic support through project CTQ2009/13459/C05/05. Also, Chemical Engineer A. Espejo thanks Gobierno de Extremadura for providing her a FPI grant.

\section{References}

[1] Z. Moldovan, Occurrences of pharmaceutical and personal care products as micropollutants in rivers from Romania. Chemosphere 64 (2006) 1808-1817.

[2] S.L. Bartelt-Hunt, D.D. Snow, T. Damon, J. Shockley, K. Hoagland, The occurrence of illicit and therapeutic pharmaceuticals in wastewater effluent and surface waters in Nebraska. Environmental Pollution 157 (2009) 786-791.

[3] J.L. Santos, I. Aparicio, M. Callejón, E. Alonso, Occurrence of pharmaceutically active compounds during 1-year period in wastewaters from four wastewater treatment plants in Seville (Spain). Journal of Hazardous Materials 164 (2009) 1509-1516.

[4] W.J. Sim, J.W. Lee, J.E. Oh, Occurrence and fate of pharmaceuticals in wastewater treatment plants and rivers in Korea. Environmental Pollution 158 (2010) 1938-1947.

[5] Q. Sui, J. Huang, S. Deng, G. Yu, Q. Fan, Occurrence and removal of pharmaceuticals, caffeine and DEET in wastewater treatment plants of Beijing, China. Water Research 44 (2010) 417-426. 
[6] P. Calza, C. Massolino, G. Monaco, C. Medana, C. Baiocchi, Study of the photolytic and photocatalytic transformation of amiloride in water. Journal of Pharmaceutical and Biomedical Analysis 48 (2008) 315-320.

[7] D. Camacho-Muñoz, J. Martín, J.L. Santos, I. Aparicio, E. Alonso, Occurrence, temporal evolution and risk assessment of pharmaceutically active compounds in Doñana Park (Spain). Journal of Hazardous Materials 183 (2010) 602-608.

[8] G.R. Boyd, H. Reemtsma, D.A. Grimm, S. Mitra, Pharmaceuticals and personal care products (PPCPs) in surface and treated waters of Louisiana, USA and Ontario, Canada. Science of The Total Environment 311 (2003) 135-149.

[9] P.H. Roberts, K.V. Thomas, The occurrence of selected pharmaceuticals in wastewater effluent and surface waters of the lower Tyne catchment. Science of The Total Environment 356 (2006) 143-153.

[10] S.D. Kim, J. Cho, I.S. Kim, B.J. Vanderford, S.A. Snyder, Occurrence and removal of pharmaceuticals and endocrine disruptors in South Korean surface, drinking, and waste waters. Water Research 41 (2007) 1013-1021.

[11] Y. Yoon, J. Ryu, J. Oh, B.G. Choi, S.A. Snyder, Occurrence of endocrine disrupting compounds, pharmaceuticals, and personal care products in the Han River (Seoul, South Korea). Science of The Total Environment 408 (2010) 636-643.

[12] T.A. Ternes, J. Stüber, N. Herrmann, D. McDowell, A. Ried, M. Kampmann, B. Teiser, Ozonation: a tool for removal of pharmaceuticals, contrast media and musk fragrances from wastewater? Water Research 37 (2003) 1976-1982.

[13] R. Rosal, A. Rodríguez, J.A. Perdigón-Melón, M. Mezcua, M.D. Hernando, P. Letón, E. García-Calvo, A. Agüera, A.R. Fernández-Alba, Removal of pharmaceuticals and kinetics of mineralization by $\mathrm{O} 3 / \mathrm{H} 2 \mathrm{O} 2$ in a biotreated municipal wastewater. Water Research 42 (2008) 3719-3728.

[14] D. Fatta-Kassinos, M.I. Vasquez, K. Kümmerer, Transformation products of pharmaceuticals in surface waters and wastewater formed during photolysis and advanced oxidation processes - Degradation, elucidation of byproducts and assessment of their biological potency. Chemosphere 85 (2011) 693-709.

[15] B. Kasprzyk-Hordern, R.M. Dinsdale, A.J. Guwy, The removal of pharmaceuticals, personal care products, endocrine disruptors and illicit drugs during wastewater treatment and its impact on the quality of receiving waters. Water Research 43 (2009) 363-380.

[16] C. Fernández, M. González-Doncel, J. Pro, G. Carbonell, J.V. Tarazona, Occurrence of pharmaceutically active compounds in surface waters of the henares-jarama-tajo river system (madrid, spain) and a potential risk characterization. Science of The Total Environment 408 (2010) 543-551.

[17] T. Deblonde, C. Cossu-Leguille, P. Hartemann, Emerging pollutants in wastewater: A review of the literature. International Journal of Hygiene and Environmental Health 214 (2011) 442-448.

[18] R. Rosal, A. Rodríguez, J.A. Perdigón-Melón, A. Petre, E. García-Calvo, M..J. Gómez, A. Agüera, A.R. Fernández-Alba, Occurrence of emerging pollutants in urban wastewater and their removal through biological treatment followed by ozonation. Water Research 44 (2010) 578-588.

[19] W.A. Moore, R.C. Kroner, C.C. Ruchhoft, Dichromate Reflux Method for Determination of Oxygen Consumed. Anal.Chem. 21 (1949) 953-957. 
[20] J. Means, S. Anderson, Comparison of five different methods for measuring biodegradability in aqueous environments. Water Air Soil Pollut 16 (1981) 301-315.

[21] L.L. Stookey, Ferrozine---a new spectrophotometric reagent for iron. Anal.Chem. 42 (1970) $779-781$.

[22] $\mathrm{H}$. Bader, J. Hoigné, Determination of ozone in water by the indigo method. Water Research 15 (1981) 449-456.

[23] W.F. Ten Berge, Breeding Daphnia magna. Hydrobiologia 59 (1978) 121-123.

[24] Organization for Economic Cooperation and Development (OECD). Daphnia sp. Acute Immobilization Test. 2004. Test Guideline No. 202, OECD Guidelines for Testing of chemicals.

[25] D. Dionisi, L. Bertin, L. Bornoroni, S. Capodicasa, M.P. Papini, F. Fava, Removal of organic xenobiotics in activated sludges under aerobic conditions and anaerobic digestion of the adsorbed species. J.Chem.Technol.Biotechnol. 81 (2006) 1496-1505.

[26] J. Radjenović, M. Petrović, D. Barceló, Fate and distribution of pharmaceuticals in wastewater and sewage sludge of the conventional activated sludge (CAS) and advanced membrane bioreactor (MBR) treatment. Water Research 43 (2009) 831841.

[27] G. Byrns, The fate of xenobiotic organic compounds in wastewater treatment plants. Water Research 35 (2001) 2523-2533.

[28] J. Stevens-Garmon, J.E. Drewes, S.J. Khan, J.A. McDonald, E.R.V. Dickenson, Sorption of emerging trace organic compounds onto wastewater sludge solids. Water Research 45 (2011) 3417-3426.

[29] K.C. Hyland, E.R.V. Dickenson, J.E. Drewes, C.P. Higgins, Sorption of ionized and neutral emerging trace organic compounds onto activated sludge from different wastewater treatment configurations. Water Research 46 (2012) 1958-1968.

[30] S.F. Yang, C.F. Lin, C.J. Wu, K.K. Ng, A. Yu-Chen Lin, P.K. Andy Hong, Fate of sulfonamide antibiotics in contact with activated sludge - Sorption and biodegradation. Water Research 46 (2012) 1301-1308.

[31] W. Feng, D. Nansheng, Photochemistry of hydrolytic iron (III) species and photoinduced degradation of organic compounds. A minireview. Chemosphere 41 (2000) 1137-1147.

[32] E.M. Rodríguez, G. Fernández, P.M. Á Ivarez, R. Hernández, F.J. Beltrán, Photocatalytic degradation of organics in water in the presence of iron oxides: Effects of pH and light source. Applied Catalysis B: Environmental 102 (2011) 572-583.

[33] F.J. Beltrán, A. Aguinaco, J.F. García-Araya, A. Oropesa, Ozone and photocatalytic processes to remove the antibiotic sulfamethoxazole from water. Water Research 42 (2008) 3799-3808.

[34] J.F. García-Araya, F.J. Beltrán, A. Aguinaco, Diclofenac removal from water by ozone and photolytic TiO2 catalysed processes. J.Chem.Technol.Biotechnol. 85 (2010) 798804.

[35] F.J. Rivas, F.J. Beltrán, A. Encinas, Removal of emergent contaminants: Integration of ozone and photocatalysis. Journal of Environmental Management 100 (2012) 10-15. 
[36] F.J. Rivas, F.J. Beltrán, O. Gimeno, B. Acedo, Wet Air Oxidation Of Wastewater From Olive Oil Mills. Chem.Eng.Technol. 24 (2001) 415-421.

[37] O. Gimeno, M. Carbajo, F.J. Beltrán, F.J. Rivas, Phenol and substituted phenols AOPs remediation. Journal of Hazardous Materials 119 (2005) 99-108.

[38] F.J. Beltrán, O. Gimeno, F.J. Rivas, M. Carbajo, Photocatalytic ozonation of gallic acid in water. J.Chem.Technol.Biotechnol. 81 (2006) 1787-1796.

[39] A. Aguinaco, F.J. Beltrán, J.F. García-Araya, A. Oropesa, Photocatalytic ozonation to remove the pharmaceutical diclofenac from water: Influence of variables. Chemical Engineering Journal 189-190 (2012) 275-282.

[40] A.G. Trovó, R.F. Pupo Nogueira, A. Agüera, A.R. Fernandez-Alba, S. Malato, Degradation of the antibiotic amoxicillin by photo-Fenton process - Chemical and toxicological assessment. Water Research 45 (2011) 1394-1402.

[41] A.G. Trovó, R.F. Pupo Nogueira, A. Agüera, A.R. Fernandez-Alba, S. Malato, Paracetamol degradation intermediates and toxicity during photo-Fenton treatment using different iron species. Water Research 46 (2012) 5374-5380.

[42] F.J. Beltrán Ozone Reaction Kinetics for Water and Wastewater Systems, Lewis Publisher, Boca Ratón, Florida, 2004.

[43] F. Javier Rivas, J. Sagasti, A. Encinas, O. Gimeno, Contaminants abatement by ozone in secondary effluents. Evaluation of second-order rate constants. J.Chem.Technol.Biotechnol. 86 (2011) 1058-1066.

[44] M.M. Huber, S. Canonica, G.Y. Park, U. von Gunten, Oxidation of Pharmaceuticals during Ozonation and Advanced Oxidation Processes. Environ.Sci.Technol. 37 (2003) 1016-1024.

[45] F.J. Real, J.L. Acero, F.J. Benitez, G. Roldán, L.C. Fernández, Oxidation of hydrochlorothiazide by UV radiation, hydroxyl radicals and ozone: Kinetics and elimination from water systems. Chemical Engineering Journal 160 (2010) 72-78.

[46] J. Benner, E. Salhi, T. Ternes, U. von Gunten, Ozonation of reverse osmosis concentrate: Kinetics and efficiency of beta blocker oxidation. Water Research 42 (2008) 3003-3012.

[47] F.J. Beltrán, A. Aguinaco, J.F. García-Araya, Mechanism and kinetics of sulfamethoxazole photocatalytic ozonation in water. Water Research 43 (2009) 13591369.

[48] J.C. Charpentier, Mass Transfer Rates in Gas Liquid Absorbers and Reactors, Advances in: Chemical Engineering, Academic Press, New York, 1981.

[49] P.N. Johnson, R.A. Davis, Diffusivity of Ozone in Water. J.Chem.Eng.Data 41 (1996) 1485-1487.

[50] F.J. Beltrán, Theoretical Aspects Of The Kinetics Of Competitive Ozone Reactions In Water. Ozone: Science \& Engineering 17 (1995) 163-181. 
List of Tables

Table 1 Wastewater characterization before pharmaceuticals spiking

Table 2 Absorbance wavelength and retention time for the HPLC separation of the pharmaceuticals mixture.

Table 3 Ozone consumption per TOC removed during ozone processes in $7 \mathrm{~h}$ biologically treated wastewater doped with pharmaceuticals studied. ${ }^{\text {a }}$

Table 4 BOD, COD and biodegradability as BOD/COD for the secondary wastewater used before and after the biological and chemical experiments ${ }^{\mathrm{a}}$

Table 5 Ecotoxicity results of Daphnia Magna immobilisation tests

Table 6 Hatta values for the ozone-pharmaceutical direct reactions ${ }^{a}$

Table 7 Relative importance of the direct reaction, \% 
List of Figure captions:

Figure 1. Chemical structures of the nine emerging compounds used in this study

Figure 2. Aerobic biological treatment setup

Figure 3. Experimental set-up for advanced oxidation processes

Figure 4. Changes with time of pharmaceuticals remaining dimensionless concentration during biological oxidation. Conditions: temperature: $20^{\circ} \mathrm{C}, \mathrm{pH}: 7.5$, Dissolved oxygen concentration: $3.0 \mathrm{mg} \cdot \mathrm{L}^{-1}$, Initial MLVSS: $1.0 \mathrm{~g} \cdot \mathrm{L}^{-1}$, Total initial concentration of pharmaceuticals: $1.8 \mathrm{mg} \cdot \mathrm{L}^{-1}$. Symbols: $\bullet$ AAF; ०: ANT; $\boldsymbol{\Delta}$ : CAF; ×: CRB; $\Delta$ : DCF; ৩: HCT; $\square:$ KET; $\mathbf{m : ~ M E T ; ~ \bullet : ~ S M X . ~}$

Figure 5. Changes of TOC with time during biological oxidation. Conditions as in Figure 4.

Figure 6. Changes with time of ANT (a), HCT (b) and KET (c) remaining dimensionless concentration during the ozone processes applied to pharmaceutical compounds mineralization in 7 hours laboratory biologically treated wastewater. Conditions: temperature: $20^{\circ} \mathrm{C}, \mathrm{pH} 3$, (buffered systems), gas flow rate: $35 \mathrm{~L} \cdot \mathrm{h}^{-1}$, inlet ozone gas concentration: $13 \mathrm{mg} \cdot \mathrm{L}^{-1}$, Total pharmaceutical concentration after biological treatment: $1.3 \mathrm{mgL}^{-1}, \mathrm{Fe}^{3+}$ concentration: $2.8 \mathrm{mg} \cdot \mathrm{L}^{-1}, \mathrm{Fe}_{3} \mathrm{O}_{4}$ concentration: $150 \mathrm{mg} \cdot \mathrm{L}^{-1}$ initial TOC: $26 \mathrm{mg} \cdot \mathrm{L}^{-1}$. Symbols: $: \mathrm{O}_{3} ; \mathbf{m}: \mathrm{O}_{3} / \mathrm{Fe}^{3+} / \mathrm{BL} ; \boldsymbol{\Delta}: \mathrm{O}_{3} / \mathrm{Fe}_{3} \mathrm{O}_{4} / \mathrm{BL}$.

Figure 7. Changes of dimensionless TOC with time during the ozone processes applied to pharmaceutical compounds mineralization in 7 hours laboratory biologically treated wastewater. Conditions and symbols as in Figure 6.

Figure 8. Changes with time of $254 \mathrm{~nm}$ absorbance during the ozone processes applied to pharmaceutical compounds mineralization in 7 hours laboratory biologically treated wastewater. Conditions and symbols as in Figure 6.

Figure 9. Variation of total iron concentration with time during the photocatalytic processes applied to pharmaceutical compounds mineralization in 7 hours laboratory biologically treated wastewater. Conditions as in Figure 6. Symbols: $\mathbf{m}: \mathrm{O}_{3} / \mathrm{Fe}^{3+} / \mathrm{BL}$; 口: $\mathrm{O}_{2} / \mathrm{Fe}^{3+} / \mathrm{BL} ; \boldsymbol{\Delta}: \mathrm{O}_{3} / \mathrm{Fe}_{3} \mathrm{O}_{4} / \mathrm{BL} ; \Delta: \mathrm{O}_{2} / \mathrm{Fe}_{3} \mathrm{O}_{4} / \mathrm{BL}$. 